\title{
中国蓄薇科植物多样性格局及其资源植物保护现状
}

\author{
邹东廷 ${ }^{1}$ 王庆刚 ${ }^{2}$ 罗 奥 $^{1}$ 王志恒 $^{*}$
}

${ }^{1}$ 北京大学城市与环境学院, 北京大学生态研究中心, 北京大学地表过程分析与模拟教育部重点实验室, 北京 $100871 ;{ }^{2}$ 中国农业大学资源与环境学院, 北京市生物多样性与有机农业重点实验室, 北京 100193

摘 要 蓄薇科(Rosaceae)是在中国广泛分布并具有重要经济价值的植物类群, 但蓄薇科资源植物的物种多样性格局及其保 护状况尚缺乏较系统的评估。该文旨在: 1)整理中国蓄薇科资源植物名录, 显示其物种多样性格局及热点地区, 并探究这一格 局的形成机制。2)评估中国蓄薇科资源植物的保护状况，为其保护规划提供基础数据。通过广泛收集整理《中国植物志》、 省级植物志等资料中关于蓄薇科的记录, 建立了中国蓄薇科物种名录(共914种), 确定了物种的主要经济用途(包括食用植物、 园林绿化植物、药用植物和水果种质资源), 并建立了每种植物的高精度分布图。在此基础上, 估算了蓄薇科全部物种及主要 资源植物类别的物种多样性格局, 并利用广义线性模型和几余分析探讨了蓄薇科物种多样性格局与环境的关系。最后将物种 分布与中国国家级和省级自然保护区进行叠加分析, 评估了蓄微科植物的保护现状。结果显示: 1)四川盆地北部、东部和西 部山区以及横断山区是中国蓄薇科植物的热点地区。2)蓄薇科植物多样性主要受水分因子影响。3)横断山区、云南东南部和 西藏东南部等地是保护薄弱物种集中的区域, 而悬钩子属(Rubus)等类群的保护不足。

关键词 蓄薇科; 物种多样性; 水分因子; 资源植物; 植物多样性保护; 自然保护区

邹东廷, 王庆刚, 罗奥, 王志恒 (2019). 中国蓄薇科植物多样性格局及其资源植物保护现状. 植物生态学报, 43, 1-15. DOI: 10.17521/cjpe.2018.0091

\section{Species richness patterns and resource plant conservation assessments of Rosaceae in China}

\author{
ZOU Dong-Ting ${ }^{1}$, WANG Qing-Gang ${ }^{2}$, LUO Ao ${ }^{1}$, and WANG Zhi-Heng ${ }^{1 *}$ \\ ${ }^{1}$ Institute of Ecology and Key Laboratory for Earth Surface Processes of the Ministry of Education, College of Urban and Environmental Sciences, Peking \\ University, Beijing 100871, China; and ${ }^{2}$ College of Resources and Environmental Sciences, and Key Laboratory of Biodiversity and Organic Farming of Bei- \\ jing City, China Agricultural University, Beijing 100193, China
}

\section{Abstract}

Aims Rosaceae is a widely-distributed family with numerous economic resource plants in China. However, the species richness pattern and the current conservation status of resource plants remain poorly evaluated. Here we aim to identify the economic resource plants of Rosaceae in China, estimate the species richness patterns for all Rosaceae plants combined and for different resource groups and evaluate the relationships between species richness patterns and environmental variables. We also evaluate the current conservation status of economic resource plants of Rosaceae.

Methods We first made the species list of all 914 Rosaceae species in China and identified the species with different economic usages, including edible, ornamental, medicinal plants and fruit germplasm resources. We then collected high-resolution distribution maps of all Rosaceae species, estimated the species richness patterns by overlapping these maps, and identified the diversity hotspots of different species groups. With high-resolution environmental data, we compared the effects of different environmental variables on the species richness and species composition of all Rosaceae species combined and the four main resource groups using generalized linear models (GLM) and redundancy analysis (RDA). Finally, we evaluated the conservation status of Rosaceae with distribution data overlaid by maps of nature reserves of China in ArcGIS.

Important findings 1) The species richness hotspots of Rosaceae in China are mainly located in the mountain areas in the north, east and west of Sichuan basin as well as Hengduan Mountains. 2) Species richness patterns of Rosaceae are mainly determined by humidity factors. 3) Poorly protected species are mainly in Hengduan Mountains, Southeast Yunnan and Xizang, and concentrated in the genus of Rubus.

收稿日期Received: 2018-04-18 接受日期Accepted: 2018-05-29

基金项目：国家重点基础研究发展计划(2017YFA0605101)和国家自然科学基金(31522012、31470564和31621091)。Supported by the National Basic Research Program of China (2017YFA0605101), and the National Natural Science Foundation of China (31522012, 31470564 and 31621091 ).

* 通信作者Corresponding author (zhiheng.wang@pku.edu.cn) 
Key words Rosaceae; species richness; humidity; plant resource; plant diversity conservation; natural reserve

Zou DT, Wang QG, Luo A, Wang ZH (2019). Species richness patterns and resource plant conservation assessments of Rosaceae in China. Chinese Journal of Plant Ecology, 43, 1-15. DOI: 10.17521/cjpe.2018.0091

地球上不同区域物种多样性存在着差异, 即生 物多样性的空间格局。这一格局的成因一直是生态 学和生物地理学的核心问题(Gaston, 2000; Wang et al., 2012a)。研究物种多样性的空间格局及其成因不 仅可以加深对不同区域的地质历史、环境变迁、生 物演化和迁移等重要生物地理学过程的认识 (Ricklefs, 2004), 也有助于提升人们对物种多样性 和资源的保护能力。从 20 世纪末以来, 科学家对这 类问题进行了大量探讨(Wang et al., 2012a), 目前关 于物种多样性空间格局的成因已有百余种理论假说 (Palmer \& White, 1994; 王志恒等, 2009), 但不同假 说的相对作用仍存在广泛争议。

物种多样性空间格局被认为是现代环境和进 化历史共同作用的结果(Brown, 2014)。现代环境因 素主要包括现代气候和生境异质性。现代气候(如水 热条件、气候季节性等)可以影响一个地区的物种承 载力(即水热条件较好、气候季节性较低的地区可以 承载更多的物种), 从而影响物种多样性的格局 (Currie, 1991; O’Brien, 1993; McGlone, 1996)。如能 量和水分条件较差的地区植物的光合作用(Schneider \& Childers, 1941)、水分运输(Cavender-Bares et al., 2005)和生殖(Morales et al., 2013)等过程都可能 受到不同程度的限制, 故植物在这些地区的分布也 会受到限制, 表现为物种多样性较低(Whittaker et al., 2007; Xu et al., 2013)。生境异质性可提供多样化 的生存环境, 为物种的共存提供更多的生态位, 并 且生境异质性较高的山地地区可以作为极端气候下 的避难所, 从而容纳更多物种(Stein et al., 2014; Shrestha et al., 2018)。物种多样性格局还受进化历 史的影响。进化历史因素主要在物种形成和物种扩 散两方面起作用。造山运动等地质活动可以加快进 化过程, 从而促使新物种快速分化, 增加地区的物 种多样性(Fjeldså et al., 2012; Hughes \& Atchison, 2015)。同时物种扩散受到生态位保守性的制约。生 态位保守性假说认为物种多样性格局受到其祖先生 态位的影响, 由于进化限制物种更倾向于保有其祖 先所在的气候生态位, 更难适应其他气候条件, 故 气候条件和某类群祖先生态位差距越大的地区, 该 类群的物种多样性越少(Wiens \& Donoghue, 2004;
Wang et al., 2011; Xu et al., 2013)。此外, 历史气候 变化也被认为是影响物种扩散和多样性格局的重要 因素。如末次冰期气候较温和的地区会有更多的物 种生存下来而非迁移或绝灭, 从而现代气候与冰期 差异较小的地区物种多样性较高(Svenning \& Skov, 2007a; Liu et al., 2017)。影响不同类群物种多样性格 局因素的相对重要性尚没有一致性的结论(Shrestha et al., 2018), 同一类群在不同地区的多样性格局也 可能受不同因素控制。故对于特定类群、特定地区 而言其物种多样性格局的形成机制仍值得研究。

资源物种是对人类生产生活具有直接或潜在 经济价值的物种, 包括野生可收获植物 (wild harvested plants)和作物的野生近缘种 (crop wild relatives), 前者可以直接为人类提供食物和原材料并衍 生相关产业, 后者则作为现代作物的种质资源在作 物育种中起到巨大的作用(Brehm et al., 2010; Sher et al., 2012)。资源物种包括食用、药用、园林绿化 观赏、油料、糖料、蜜源、木材、牧草、纤维等类 别, 以及对应的种质资源(近缘种)等(俞德浚等, 1989)。资源物种由于对人类的经济社会发展意义重 大, 应该受到优先保护, 但传统保护生物学关于物 种保护优先级的评估更关注物种的受威胁性而对物 种的经济价值较为忽视(Brehm et al., 2010)。所以资 源物种的多样性格局及热点地区更应该受到关注, 以凸显其在植物保护方面的意义。

蓄薇科是北半球温带地区具有代表性的一个 科, 全球有3亚科, 88-100属, 约3 000种(Xiang et al., 2017), 中国有 51 属 1000 余种 (Wu \& Raven, 1994-2009)。蓄薇科包含桃亚科(Amygdaloideae)、 蓄薇亚科(Rosoideae)和仙女木亚科(Dryadoideae)三 个亚科, 其中桃亚科和萻薇亚科包含许多常见的水 果(如苹果Malus domestica、桃Amygdalus persica、 草莓Fragaria $\times$ ananassa)、花卉(如月季花Rosa chinensis) 和药材种类, 对人类的生产生活具有重大 经济价值(Zhang et al., 2017)。目前对蓄薇科的研究 主要集中于基因与进化(Amsellem et al., 2000; Fan et al., 2013; Ru et al., 2015)、生理学(Wells et al., 2002; Wheeler et al., 2005; Lin-Wang et al., 2010)、系 统学(Lee \& Wen, 2001; Potter et al., 2007; Shi et al., 
2013)等方面研究。然而, 关于蓄薇科物种多样性格 局及其保护的相关研究只有少量的报道(如伊朗的 蓄微科(Peyravi, 2015)和秘鲁安第斯山区Polylepis属 (Mendosa \& Cano, 2011))。尤其是蓄薇科植物极为 丰富的中国尚没有蓄薇科及其资源植物的多样性格 局保护研究报道, 主要原因是缺少较精细分辨率的 国家尺度上的分布数据。

针对上述问题, 本研究利用较为精细的物种分 布数据 $(50 \mathrm{~km} \times 50 \mathrm{~km})$, 分析中国萻薇科及其资源 植物的物种多样性格局, 评估其保护状况。具体而 言, 本研究着重探索了以下问题: 1)中国蓄薇科整 体及各类资源植物物种多样性格局如何? 其热点地 区分布在什么区域? 中国蓄薇科物种多样性与气 候、地形和过去气候变化等环境因子具有怎样的关 系? 2)中国蓄薇科植物, 特别是其中的资源植物受 保护的状况如何?

\section{1 材料和方法}

\section{1 数据与材料}

\subsection{1 物种名录}

本研究所使用的蓄薇科物种名录主要来自 《Flora of China》修订版(Wu \& Raven, 1994-2009), 并依据其异名和接受名体系确定了本文中国蓄薇科 物种接受名名录。在此基础上, 我们去除了外来种 和原产地无法确定的栽培种, 并将种下单位合并至 种水平。最终结果显示, 中国境内共有蓄薇科物种 914 个。

蓄微科物种的经济用途很广。本研究按照经济 用途, 将蓄薇科物种归为食用(包括提供淀粉和寡 糖)、园林绿化、药用和水果种质资源 4 类资源植物。 其中, 食用植物类参考了《中国植物志》第36-38卷 (俞德浚等, 1989)、《中国食用本草——植物卷》(郑 汉臣等, 2003)、《中国经济植物志》(中华人民共和 国商业部土产废品局和中国科学院植物研究所, 2012)等资料。园林绿化植物类参考了《中国植物志》 第36-38卷(俞德浚等, 1989)、《园林景观植物树木图 典》(汪荣先, 2010)、《园林植物 1000 种》 (刘与明和 黄全能, 2012)、《园林景观植物图鉴》(周洪义, 2009)、 《中国作物及其野生近缘植物——花卉卷》(董玉琛 和刘旭, 2007) 以及《经济植物手册》(胡先骕, 1955) 等资料。药用植物类参考了《中国药用植物志》(艾 铁民, 2016)、《中国药用植物图鉴》(第二军医大学
药学系生药学教研室, 1960)、《中国药用植物(一)》 (叶华谷等, 2014)、《中国植物志》第36-38卷(俞德浚 等, 1989)和《中国经济植物志》(中华人民共和国商 业部土产废品局和中国科学院植物研究所, 2012)等 资料。水果种质资源类根据《中国植物志》第36-38 卷(俞德浚等，1989)等共计76部(篇)文献，由于参考 资料较多, 故列于附录 I。

根据近期发表的《中国高等植物受威胁物种名 录》(覃海宁等, 2017), 我们标记了中国蓄薇科物种 的濒危等级。这一名录反映了目前对中国高等植物 受威胁情况最全面的评估。根据IUCN濒危物种红色 名录标准，濒危等级分为极危 $(\mathrm{CR})$ 、濒危 $(\mathrm{EN})$ 和易 危(VU)。对同一个物种的不同种下单位有不同濒危 等级的, 则按照 VU-EN-CR 的顺序全部标记 (如 EN-CR, VU-EN等)。结果显示, 中国蓄薇科共有 58 个受威胁物种。

中国萻薇科全部物种名录、每个物种所属资源 类型及受威胁状况等信息见附录II。

\subsection{2 物种分布数据}

本研究所使用的物种分布数据来自《中国木本 植物分布图集》(Fang et al., 2011; Wang et al., 2011)、 中国国家标本资源平台(http://www.nsii.org.cn/)、“中 国种子植物” 数据库以及部分省级植物志, 并用 《Flora of China》修订版(Wu \& Raven, 1994-2009) 进行了校对。物种分布数据的空间分辨率为县级。 为增加物种分布数据的准确性, 我们在收集物种分 布数据时, 将中国西部地区(特别是新疆南部、西藏 北部)部分面积较大的县划分为多个部分，并根据 物种的分布生境、海拔等信息确定物种在这些县内 的分布区域。全部空间分布单元的面积中位数为 $1960.54 \mathrm{~km}^{2}$ 。为了消除面积对物种多样性估算的影 响, 本研究用Arcgis 9.3 (ESRI, Redlands, CA) 将县 级分布数据转化为阿尔伯斯投影(正轴等积割圆雉 投影)下分辨率为 $50 \mathrm{~km}$ 的网格形式，同时去掉了位 于边界地区(包括陆上国界与海岸线)且边界内部面 积小于网格大小一半 $\left(1250 \mathrm{~km}^{2}\right)$ 的网格。另外, 由 于数据限制, 本研究未包含台湾和海南岛以外的其 他岛屿。最终, 研究区共有 3794 个网格用于后续物 种多样性格局估算及统计分析。附录II显示了每个 物种分布区所涵盖的网格数。

\subsection{3 环境数据}

本研究所使用的气候数据包括现代气候数据、 
末次冰期气候数据以及生境异质性数据, 其中, 现 代气候因子分为气温、降水和气候季节性。温度因 子包括年平均气温 $(M A T)$ 、最冷季平均气温 $(M T C Q)$ 、最暖季平均气温 $(M T W Q)$ 。降水因子包括 年降水量 $(A P)$ 、湿润指数 $(M I)$ 和年实际蒸散量 $(A E T)$ 。气候季节性因子包括温度季节性 $(T S N)$ 和降 水季节性 $(P S N)$ 。其中, $M A T 、 M T C Q 、 M T W Q 、 A P$ 、 $T S N$ 和 $P S N$ 数据来自Worldclim网站(Hijmans et al., 2005), 原始分辨率为 $1^{\prime}$, 在Arcgis 10.0 (ESRI, Redlands, CA)中重采样到 $50 \mathrm{~km}$ 。TSN定义为月平均气 温的标准差, 而 $P S N$ 则定义为月降水量的变异系数 (Hijmans et al., 2005)。AET和MI按照Thornthwaite和 Hare (1955)的方法计算得到, 分别反映了在降水限 制下地区实际可以蒸散的水分以及在考虑了潜在蒸 散后的水分供应状况(Mccabe et al., 1990)。

生境异质性因子包括海拔高差 $(E L E R)$ 、年平均 气温空间差异 $(M A T R)$ 和年降水量空间差异 $(A P R)$ 。 $E L E R$ 由每个网格中最高和最低海拔的差值计算而 来, 用以表现地形的复杂性(Kerr \& Packer, 1997)。 海拔数据来自数字地形模型 GTOPO30 (http://eros.usgs.gov/\#/Find_Data/Products_and_Data Available/gtopo30_info), 原始分辨率为3", 重采样 到 $100 \mathrm{~m}$ 。类似地, MATR和 $A P R$ 由每个网格中最高的 年平均气温(年降水量)与最低的年平均气温(年降水 量)的差值计算而来。由于生境异质性因子均呈显著 右偏分布, 参考以往研究(如Wang et al., 2011), 在 后续统计分析中, 这些变量均取自然对数。

末次盛冰期(LGM) 以来的气候变化包括LGM 以来的年平均气温变化(anomaly_MAT)、LGM以来 的年降水量变化(anomaly_AP)、LGM以来年平均气 温变化的空间迁移速率(velocity_MAT) 以及LGM以 来年降水量变化的空间迁移速率(velocity_AP)。 anomaly_MAT 和anomaly_ $A P$ 为LGM 时期 $M A T(A P)$ 和现代 $M A T(A P)$ 的差值 [即 $\left(M A T_{\text {present }}-M A T_{\mathrm{LGM}}\right)$ 和 $\left.\left(A P_{\text {present }}-A P_{\mathrm{LGM}}\right)\right]($ Sandel et al., 2011), 反映了LGM 时期以来各地气候变化的幅度。velocity_MAT和 velocity_AP则表示为了追踪 $M A T$ 或 $A P$ 的变化, 生物 从LGM时期到现代平均每年需要迁移的距离。这些 指标和该地区LGM时期以来的气候变化速率有关, 同时和该地区地形复杂度、植被类型等因素有关 (Loarie et al., 2009)。Velocity的计算方法参见Loarie 等(2009)。LGM时期的气候数据来自Worldclim网站,
由大气环流模型 $(\mathrm{GCM})$ 计算而来, 利用统计方法降 尺度到分辨率2.5' (Hijmans et al., 2005)。在计算 LGM 时期气候数据的过程中, 有 3 种常用的 GCM模 型—MIROC-ESM (Watanabe et al., 2011), CCSM v3 (Collins \& Halliday, 2005)和CCSM v4 (Gent \& Danabasoglu, 2011)。Kimura等(2014)的研究表明, MIROC-ESM模型重建的气候数据对过去植被分布 的复原准确度高于 CCSM模型, 且方差小于CCSM 模型。故本研究采用MIROC-ESM模型的重建结果 (Wang et al., 2017)。各环境变量之间的Pearson相关 系数显示在附录III中。

\subsection{4 保护区分布数据}

中国自然保护区分布数据来自Zhang等(2015)。 该数据库收集了截至2012年底中国建立的334个国 家级自然保护区和 857 个省级自然保护区的数字边 界, 并记录了保护区的位置、面积、保护标的等基 本信息。本数据库不包含台湾岛的数据。

\section{2 研究方法}

\subsection{1 物种多样性格局与环境因子的关系}

首先, 我们利用 $50 \mathrm{~km} \times 50 \mathrm{~km}$ 的物种分布数据, 估算了每个网格中的物种多样性, 并用Arcgis 10.5 绘制了蓄微科全部物种的物种多样性格局。其次, 根据物种名录, 我们分别估算了四类资源植物(即 食用植物、园林绿化植物、药用植物和水果种质资 源)的物种多样性格局。第三, 我们估算了每个网格 内每类资源植物占全部物种的比例, 并绘制了其地 理格局。第四, 我们定义每类资源植物物种多样性 最高的 $5 \%$ 的网格(物种数为 0 的网格不计)为其多样 性热点地区(Orme et al., 2005; Shrestha et al., 2018)。 然后将四类资源植物的热点地区进行叠加, 篮选出 每类资源植物独有的热点地区以及两类、三类和四 类资源植物共有的热点地区，分别定义为“单一热 点”、“二类热点”、“三类热点”和“四类热点”, 并分 析了这些热点地区的保护价值。

基于物种多样性格局和各类环境因子, 本研究 通过具有泊松残差的广义线性回归模型分析了蓄薇 科全部物种和各类资源植物物种多样性与环境因子 之间的关系, 并提取了模型的回归系数(即环境因 子每变动一个单位, 物种多样性变化的大小) 和 Pseudo- $R^{2}$, 以评估二者相关性强弱(Shrestha et al., 2018)。为进一步分析物种分布与环境因子的关系, 我们以物种分布矩阵为因变量, 和环境因子矩阵为

www.plant-ecology.com 
约束变量进行冗余分析(RDA), 提取了物种得分与 环境因子得分的前两个RDA轴, 在二维图上显示, 以探究物种分布与环境因子的关系。

\subsection{2 蓄薇科物种的保护现状与保护弱点分析}

首先，我们将中国的国家级和省级自然保护区 显示在地图上, 并和一至四类热点地区地图进行叠 加并制图, 以直观地显示这些热点地区受保护的状 况。对于每一个网格, 我们计算了自然保护区在其 中的面积和个数, 并以如下 4 个指标评估了其受保 护的状况。1)有无保护区覆盖。当网格内保护区面 积不小于 $5 \mathrm{~km}^{2}$ (这一数值为最小保护区的面积)时, 认为该网格被保护区覆盖。实际共录得 1849 个被 保护区覆盖的网格。2)网格内的保护区个数。只有 在一个网格被保护区覆盖时, 才将其计入保护区 个数。3)保护区覆盖面积占网格面积的比例。4)保 护区覆盖面积是否小于网格面积的 $10 \%$ 。这些指标 可以从不同方面反映每一个网格受保护的状况。对 于热点地区, 我们重点提取了菩薇科全部物种的热 点地区、各类资源植物的热点地区以及一至四类热 点地区, 并计算了热点地区网格内上述 4 个评价 指标的均值, 用以反映不同类别热点地区受保护的 状况。

其次, 我们从物种的总分布范围和其在被保护 区覆盖的网格中的分布范围的差异考量其受保护的 程度。首先, 我们将物种分布区按照面积大小升序 排列，取前 $25 \%$ 作为狭域种(Jetz \& Rahbek, 2002; Shrestha et al., 2018), 共获得狭域种225个。其次,
将物种分布区按照其中被保护区覆盖的网格数升序 排列，取前 $25 \%$ 作为受保护较差的物种，共获得 226 种。第三，将狭域种和受保护较差的物种取交集，作 为保护薄弱物种, 共计 209 种。我们认为这些物种是 蓄薇科植物的保护薄弱物种。接下来, 我们估算了 保护薄弱物种的多样性格局, 并在Arcgis 10.5中制 图, 以确定蓄薇科物种的保护薄弱区(亦即保护优 先区)。同时, 我们统计了保护薄弱物种的资源类型, 以探究哪种资源类型的蓄薇科植物更缺乏保护。

最后, 本研究比较了蓄薇科不同属内资源植物 的数量及受保护状况的差异。根据物种名录, 我们 篮选出物种数量超过 15 的属, 分析了其各类资源植 物的种数。在此基础上, 我们计算了各属保护薄弱 物种的种数及其占该属全部物种的比例, 以评估资 源植物被保护状况是否存在属间差异。

全部的计算与分析工作在R v3.3 (https://cran. r-project.org/)中完成。

\section{2 结果}

蓄薇科的资源物种主要集中在一些物种数量较 多的属(如悬钩子属Rubus、菩薇属Rosa和委陵菜属 Potentilla)和另一些较小的木本植物属(如苹果属 Malus和山楂属Crataegus)内(表1)。几个较大的属的 主要资源类型各具特色: 如悬钩子属主要以水果种 质资源为主，萻薇属主要以园林花卉为主，而委陵 菜属主要以药用植物为主。而较小的木本植物属则 主要拥有高比例的水果种质资源(表1)。

表1 蓄薇科内超过 15 个物种的属及其资源和保护薄弱物种状况

Table 1 Numbers of resources plant species and poorly protected species in genera with $\geqslant 15$ species in Rosaceae

\begin{tabular}{|c|c|c|c|c|c|c|c|c|}
\hline $\begin{array}{l}\text { 属名 } \\
\text { Genus name }\end{array}$ & $\begin{array}{l}\text { 物种总数 } \\
\text { Number of } \\
\text { species }\end{array}$ & $\begin{array}{c}\text { 保护薄弱物 } \\
\text { 种数(比例) } \\
\text { Number (propor- } \\
\text { tion) of poorly } \\
\text { protected species }\end{array}$ & $\begin{array}{c}\text { 食用植物 } \\
\text { Edible plants }\end{array}$ & $\begin{array}{c}\text { 园林植物 } \\
\text { Ornamental } \\
\text { plants }\end{array}$ & $\begin{array}{c}\text { 药用植物 } \\
\text { Medicinal } \\
\text { plants }\end{array}$ & $\begin{array}{c}\text { 水果种质资源 } \\
\text { Fruit germpla- } \\
\text { sm resource }\end{array}$ & $\begin{array}{c}\text { 资源物种总数 } \\
\text { Total number } \\
\text { of resource } \\
\text { species }\end{array}$ & $\begin{array}{c}\text { 保护薄弱的资源 } \\
\text { 物种总数(比例) } \\
\text { Number (proportion) } \\
\text { of poorly protected } \\
\text { resource species }\end{array}$ \\
\hline 悬钩子属 Rubus & 206 & $74(0.359)$ & 27 & 10 & 63 & 171 & 175 & $51(0.291)$ \\
\hline 蓄薇属 Rosa & 94 & $27(0.287)$ & 10 & 53 & 37 & 36 & 57 & $3(0.053)$ \\
\hline 委陵菜属 Potentilla & 83 & $11(0.133)$ & 4 & 16 & 36 & 0 & 40 & 0 \\
\hline 绣线菊属 Spiraea & 67 & $13(0.194)$ & 0 & 37 & 23 & 0 & 39 & $3(0.077)$ \\
\hline 花楸属 Sorbus & 64 & $13(0.203)$ & 2 & 11 & 17 & 22 & 26 & 0 \\
\hline 栒子属 Cotoneaster & 61 & $4(0.066)$ & 0 & 20 & 16 & 55 & 58 & $3(0.052)$ \\
\hline 石楠属 Photinia & 43 & $17(0.395)$ & 0 & 7 & 9 & 1 & 10 & 0 \\
\hline 樱属 Cerasus & 38 & 0 & 5 & 13 & 15 & 19 & 23 & 0 \\
\hline 苹果属 Malus & 23 & $2(0.087)$ & 7 & 19 & 14 & 20 & 21 & $1(0.048)$ \\
\hline 山楂属 Crataegus & 18 & $5(0.278)$ & 6 & 6 & 13 & 15 & 16 & $4(0.250)$ \\
\hline 绣线梅属 Neillia & 15 & $7(0.467)$ & 0 & 6 & 3 & 0 & 6 & 0 \\
\hline
\end{tabular}


中国蓄薇科全部物种的物种多样性在西南的横 断山区和环绕四川盆地的山脉较高, 而在西北干旱 区、华北平原东部和东北平原较低。在各气候带中, 亚热带是蓄薇科物种最集中的区域(图1)。各类资源 植物的多样性格局和菩薇科全部物种的多样性格局 具有较高一致性, 但在局部有差别(图2)。对四类资 源植物热点地区的叠加图显示, 全部资源植物共有 的“四类热点”地区主要分布在四川盆地的北部、东 部和西部, 特别是秦岭、大巴山和巫山山脉区域。 “三类热点”主要集中在横断山区，以及“四类热点” 的边缘地带(图3)。虽然横断山区是全部物种及绝大 多数资源植物的多样性热点地区, 但食用植物的热

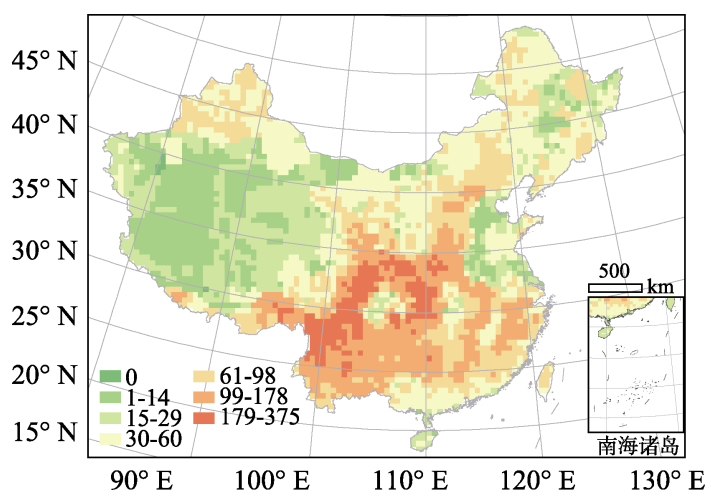

图1 中国萻薇科物种多样性格局。不同颜色表示各个网格 内蓄薇科的物种数。

Fig. 1 Species richness pattern of Rosaceae in China. Colors reflect number of Rosaceae species in each grid cell.

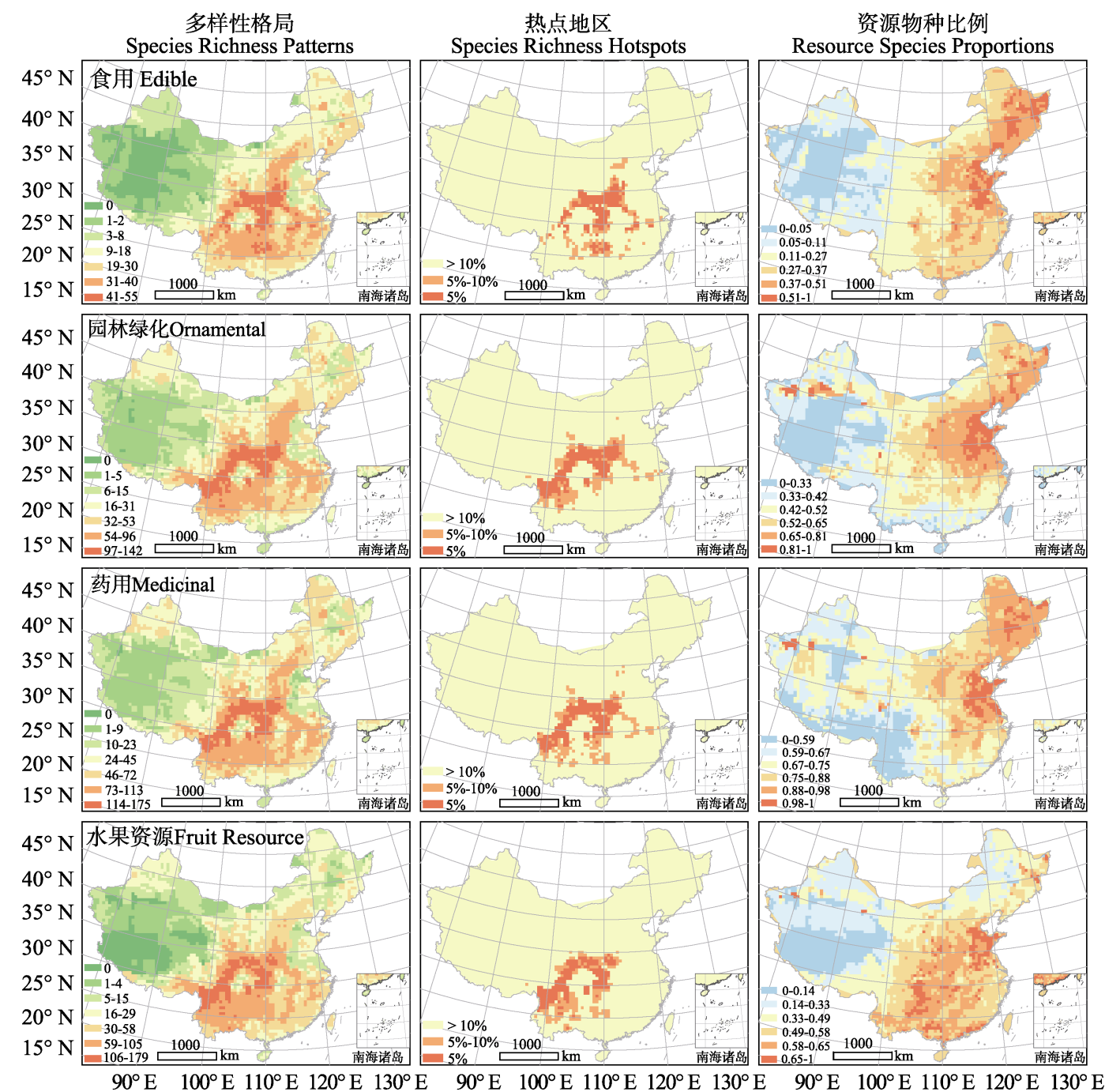

图2 中国蓄薇科各资源类别(食用植物、园林绿化植物、药用植物、水果种质资源)的物种多样性格局及其热点地区。第 一列为物种多样性格局, 第二列为热点地区(颜色表示物种丰富度在所有网格中的分位数), 第三列为资源物种占蓄薇科全 部物种的比例。

Fig. 2 Species richness patterns and hotspots of the four main resource groups (edible, ornamental, medicinal plants and fruit germplasm resources) of Rosaceae. The left column shows species richness patterns. The central column shows species richness hotspots (different colors represent different quantiles of species richness in each grid cell). The right column shows the ratios of the number of resource species and the number of all species in each grid cell. 
点地区则主要集中在秦岭、大巴山、巫山等地。各 类资源植物占全部蓄薇科物种的比例存在明显的空 间格局和类群差异。具体而言, 食用植物、园林绿 化植物和药用植物在华北平原和东北平原的比例最 高, 而水果种质资源则在华北平原东部和云贵高原 东部比例最高(图2)。

广义线性模型分析结果显示, 水分因子是菩薇 科全部物种以及各类资源植物物种多样性格局最重 要的主导因子(表2)。在所有资源类型中，只有水果 种质资源植物的多样性与温度季节性和LGM以来 的温度迁移速率具有较显著的关系(表2)。这些结果 说明，在水热条件好、水分季节性不明显的区域，蓄 薇科植物的多样性较高; 在地形起伏较大、生境异 质性较强的区域, 苗薇科多样性也较高; 而在LGM 以来气候变化较大 $(\mathrm{LGM}$ 以来温度升高、降水增加 幅度大) 以及气候变化空间迁移速率较高的地区, 蓄薇科植物多样性则较低(表2)。RDA结果显示, 物 种分布主要受两组环境梯度的影响(附录 $\mathrm{V}$ ), 主要 是沿第一 $\mathrm{RDA}$ 轴方向的 $M A T 、 M I$ 和velocity_AP等因 子和沿第二RDA轴方向的 $\log E L E R$ 、velocity_MAT 和 TSN等因子(附录IV)。

我国青藏高原和东北地区的自然保护区面积较 大，而东部和南部地区虽然保护区数量较多，但大

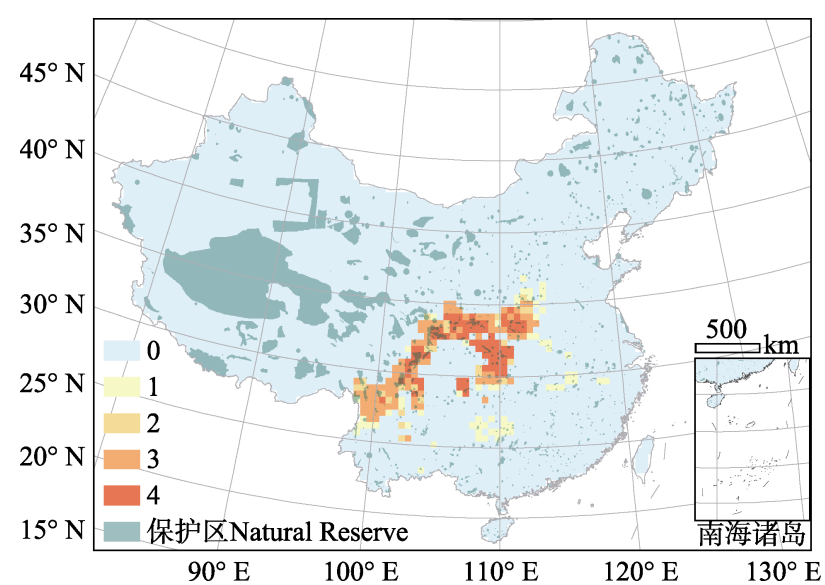

图3 中国蓄薇科各资源类别(食用植物、园林绿化植物、 药用植物、水果种质资源)物种多样性热点地区叠加图。橙 红深浅表示该热点地区资源类别的种数, 详见材料与方法 1.5。绿色表示我国国家级和省级自然保护区的分布。

Fig. 3 The overlaid map of species richness hotspots of the four resource groups (edible, ornamental, medicinal plants and fruit germplasm resources) of Rosaceae. The orange and red colors represent the number of resource groups sharing the grid cell as their hotspot (see Materials and Methods 1.5). Green color represents national and provincial natural reserves in China.
表2 蓄薇科全部物种及各资源类别(食用植物、园林绿化植物、药用植 物、水果种质资源)物种多样性格局与环境因子的关系

Table 2 Relationships between species richness patterns and environmental variables for all species combined and for the four main resource groups (i.e. edible, ornamental, medicinal plants and fruit germplasm resources) of Rosaceae

\begin{tabular}{|c|c|c|c|c|c|}
\hline $\begin{array}{l}\text { 环境变量 } \\
\text { Environmental } \\
\text { variables }\end{array}$ & $\begin{array}{l}\text { 总体 } \\
\text { All } \\
\text { species }\end{array}$ & $\begin{array}{l}\text { 食用植物 } \\
\text { Edible } \\
\text { plants }\end{array}$ & $\begin{array}{l}\text { 园林植物 } \\
\text { Ornamental } \\
\text { plants }\end{array}$ & $\begin{array}{l}\text { 药用植物 } \\
\text { Medicinal } \\
\text { plants }\end{array}$ & $\begin{array}{l}\text { 水果资源 } \\
\text { Fruit } \\
\text { Germplasn } \\
\text { Resource }\end{array}$ \\
\hline \multicolumn{6}{|l|}{$\begin{array}{l}\text { 气温 } \\
\text { Temperature }\end{array}$} \\
\hline MAT & 14.4 & 24.1 & 15.4 & 16.6 & 19.0 \\
\hline MTCQ & 21.4 & 20.5 & 18.0 & 18.1 & 29.2 \\
\hline MTWQ & 3.7 & 20.1 & 7.7 & 9.3 & 3.7 \\
\hline \multicolumn{6}{|l|}{$\begin{array}{l}\text { 降水 } \\
\text { Precipitaion }\end{array}$} \\
\hline$A P$ & 25.2 & 27.3 & 21.6 & 25.9 & 27.9 \\
\hline MI & 35.0 & 24.3 & 28.7 & 31.1 & 36.2 \\
\hline$A E T$ & 23.2 & 35.3 & 24.7 & 28.4 & 28.0 \\
\hline \multicolumn{6}{|l|}{$\begin{array}{l}\text { 气候季节性 } \\
\text { Climate } \\
\text { Seasonality }\end{array}$} \\
\hline TSN & -19.3 & -5.2 & -9.7 & -8.2 & -30.6 \\
\hline$P S N$ & -11.1 & -8.6 & -9.8 & -12.7 & -12.0 \\
\hline \multicolumn{6}{|l|}{$\begin{array}{l}\text { 生境异质性 } \\
\text { Habitat } \\
\text { heterogeneity }\end{array}$} \\
\hline $\log E L E R$ & 21.0 & 2.4 & 11.3 & 10.9 & 19.4 \\
\hline $\log M A T R$ & 20.1 & 2.0 & 10.8 & 10.2 & 18.7 \\
\hline $\log A P R$ & 9.3 & 2.3 & 5.6 & 5.8 & 7.1 \\
\hline \multicolumn{6}{|l|}{$\begin{array}{l}\text { 末次盛冰期以 } \\
\text { 来的气候变化 } \\
\text { Climate Change } \\
\text { since the LGM }\end{array}$} \\
\hline anomaly_MAT & -12.7 & -7.7 & -7.1 & -9.0 & -17.1 \\
\hline anomaly_AP & -5.5 & n.s. & -3.7 & -1.8 & -6.8 \\
\hline velocity_MAT & -25.3 & -10.6 & -17.2 & -17.4 & -30.9 \\
\hline velocity_AP & -11.5 & -15.9 & -11.9 & -10.5 & -17.8 \\
\hline
\end{tabular}

数字表示泊松回归的调整Pseudo- $R^{2}$ 值 $(\%)$, 负号表示物种多样性与环境 因子负相关, n.s.表示回归结果不显著。粗体字表示对每类物种的主导环 境变量。AET, 年实际蒸散量; anomaly_AP, 末次盛冰期以来年降水量变 化; anomaly MAT, 末次盛冰期以来年平均气温变化; $A P$, 年降水量; $A P R$, 降水量空间差异; $E L E R$, 海拔高差; $M A T$, 年平均气温; MATR, 气温度空 间差异; $M I$, 湿润指数; $M T C Q$, 最冷季平均气温; $M T W Q$, 最暖季平均气 温; PSN, 降水季节性; TSN, 温度季节性; velocity_AP, 末次盛冰期以来 年降水变化的空间迁移速率; velocity_MAT, 末次盛冰期以来年均温变化 的空间迁移速率

Pseudo- $R^{2}(\%)$ are shown by the numbers. "-" represents negative relationships and "n. s." represents non-significant relationships. The environmental variables with the highest pseudo- $R^{2}$ in each group are shown in bold. Variable abbreviations: AET, actual annual evapotranspiration; anomaly AP, AP anomaly between the present and the LGM; anomaly MAT, MAT anomaly between the present and the LGM; AP, annual precipitation; APR, range of annual precipitation; $E L E R$, elevational range; MAT, mean annual temperature; MATR, range of mean annual temperature; $M I$, moisture index; MTCQ, mean temperature of the coldest quarter; $M T W Q$, mean temperature of the warmest quarter; PSN, precipitation seasonality; TSN, temperature seasonality; velocity $A P$, spatially migration velocity to track $A P$ change since the LGM;velocity_MAT, spatially migration velocity to track MAT change since the LGM. 
多面积较小(图3)。全部资源植物共有的“四类热点” 地区(即四川盆地北部、东部和西部山区)被保护区 覆盖的程度较高, 而其他类别的热点地区(如横断 山区、秦岭北缘和东缘的部分地区)被保护区覆盖的 程度相对较低(图3)。在各类热点地区内, 被保护区 覆盖的网格比例都在 $60 \%-80 \%$, 其中药用植物热点 和“四类热点”地区被保护区覆盖的网格比例最高, 而其他类别热点地区被保护区覆盖的比例则较低 (表3)。各类热点地区内, 平均每个网格内的保护区 个数在1.11-2.01之间; 其中“四类热点”地区最高, 其他类型热点地区较低。保护区覆盖面积比例在各 类热点地区之间差异较大，介于 $6.8 \%-16.1 \%$ 之间; 其中, “四类热点”地区覆盖面积最高, 达 $16.1 \%$, 超 过全国所有保护区面积占国土面积的比例(14.9\%, 以下简称“全国平均水平”), 而其他热点地区内的保 护区覆盖面积均低于全国平均水平，尤其是“三类 热点”和“单一热点”地区，其被保护区覆盖的面积 比例仅能达到全国平均水平的 $61 \%$ 和 $46 \%$ 。在各类 热点地区内, 保护区覆盖面积小于 $10 \%$ 的网格数量 介于 $30 \%-45 \%$ 之间; 其中, 食用植物和“四类热点” 地区比例较低, 表明低保护区覆盖率(即保护区覆 盖面积小于 $10 \%)$ 的网格数量较少; 而“一类热点”、 “三类热点” 和水果种质资源热点地区的低保护区覆 盖率均超过 $40 \%$, 表明这些地区有接近一半的网格 内保护区覆盖面积低于 $10 \%$, 保护能力较弱(表3)。

在所有209种保护薄弱种中, 水果种质资源比 例最高(共计61种), 其次是园林绿化植物(12种)、药 用植物( 8 种)和食用植物( 1 种), 说明后两者得到了 较好的保护(表4)。
保护薄弱物种比例在不同属之间差异很大。在 物种数最多的 15 个属中, 保护薄弱物种比例从 0 到 $46.7 \%$ 不等。保护薄弱物种比例最高的绣线梅属有 近一半的物种都没有得到有效保护(表1)。而蓄薇科 的最大属悬钩子属中, 保护薄弱物种达 74 种, 比例 高达 $35.9 \%$, 其中有 51 种都是重要的资源物种(表 1 )。 保护薄弱物种的物种多样性格局与蓄薇科全部物种 的多样性格局有较大差异(图4)。保护薄弱物种主要 集中在横断山区、云南东南部、西藏东南部以及台 湾岛, 而在总体多样性较高的秦岭地区则几乎没有 保护薄弱物种的分布。

\section{3 讨论}

\section{1 蔷薇科物种多样性格局及其与环境因子的 关系}

蓄薇科全部植物和绝大多数资源植物的多样 性热点地区主要集中在中国西南部的横断山区，以 及四川盆地的北部、东部和西部(图1)。这和其他种 子植物类群具有相似的格局(如全部木本植物, Wang et al., 2012a; 杜鹃属(Rhododendron)植物, Shrestha et al., 2018)。综合来看, 蓄薇科的物种多样 性格局表现出三个特点: 1)南方地区物种较多;2)亚 热带物种较热带多; 3)山区物种较其他地形多。这三 个特点是分别受不同因素影响而产生的。

\subsection{1 现代气候和历史气候变化因素的作用}

首先，南方地区物种较多是现代气候因子和 LGM时期以来气候变化因子共同作用的结果。现代 气候因子的作用表现为水热条件越好、季节性越不 明显的地区物种多样性越高(表2)。RDA分析结果也

表3 蓄薇科物种多样性热点地区的保护状况

Table 3 Conservation status of species diversity hotspots of Rosaceae

\begin{tabular}{|c|c|c|c|c|c|}
\hline $\begin{array}{l}\text { 热点地区类型 } \\
\text { Type of hotspot }\end{array}$ & $\begin{array}{l}\text { 网格数 } \\
\text { Number of } \\
\text { grid cells }\end{array}$ & $\begin{array}{c}\text { 被保护区覆盖的 } \\
\text { 网格比例 } \\
\text { Proportion of grid cells } \\
\text { covered by natural } \\
\text { reserves }\end{array}$ & $\begin{array}{l}\text { 网格内保护区的 } \\
\text { 平均个数 } \\
\text { Mean number of } \\
\text { natural reserves in } \\
\text { each grid cell }\end{array}$ & $\begin{array}{c}\text { 保护区覆盖面积比例 } \\
\text { Proportion of area } \\
\text { covered by natural } \\
\text { reserves }\end{array}$ & $\begin{array}{c}\text { 保护区覆盖面积小于 } \\
10 \% \text { 的网格数量比例 } \\
\text { Proportion of grid cells } \\
\text { with }<10 \% \text { of area cov- } \\
\text { ered by natural reserve }\end{array}$ \\
\hline 所有物种 All species & 189 & 0.693 & 1.47 & 0.135 & 0.397 \\
\hline 食用植物 Edible plants & 165 & 0.721 & 1.58 & 0.102 & 0.327 \\
\hline 园林植物 Ornamental plants & 187 & 0.717 & 1.52 & 0.124 & 0.380 \\
\hline 药用植物 Medicinal plants & 185 & 0.735 & 1.55 & 0.122 & 0.373 \\
\hline 水果种质资源 Fruit germplasm resource & 172 & 0.727 & 1.57 & 0.137 & 0.424 \\
\hline 四类热点 Type IV hotspot & 78 & 0.782 & 2.01 & 0.161 & 0.333 \\
\hline 三类热点 Type III hotspot & 94 & 0.691 & 1.18 & 0.091 & 0.426 \\
\hline 二类热点 Type II hotspot & 25 & 0.680 & 1.40 & 0.116 & 0.360 \\
\hline 单一热点 Type I hotspot & 65 & 0.631 & 1.11 & 0.068 & 0.446 \\
\hline
\end{tabular}

www.plant-ecology.com 
表4 蓄薇科各资源类别(食用植物、园林绿化植物、药用植物、水果种 质资源) 内保护薄弱物种的数量

Table 4 The number of poorly protected species of the four main resource groups (edible, ornamental, medicinal plants and fruit germplasm resources) of Rosaceae

\begin{tabular}{lccc}
\hline $\begin{array}{l}\text { 资源类型 } \\
\text { Resource type }\end{array}$ & $\begin{array}{c}\text { 物种总数 } \\
\text { Total number } \\
\text { of species }\end{array}$ & $\begin{array}{c}\text { 保护薄弱物种数 } \\
\text { Number of poorly } \\
\text { protected species }\end{array}$ & $\begin{array}{c}\text { Proportion of poorly } \\
\text { protected species }\end{array}$ \\
\hline $\begin{array}{l}\text { 食用植物 } \\
\text { Edible plants }\end{array}$ & 120 & 1 & 0.008 \\
$\begin{array}{l}\text { 完林植物 } \\
\begin{array}{l}\text { Ornamental } \\
\text { plants }\end{array}\end{array}$ & 286 & 12 & 0.042 \\
$\begin{array}{l}\text { 药用植物 } \\
\text { Medicinal plants }\end{array}$ & 495 & 8 & 0.016 \\
$\begin{array}{l}\text { 水果种质资源 } \\
\text { Fruit germplasm } \\
\text { resource }\end{array}$ & 398 & 61 & 0.153 \\
\hline
\end{tabular}

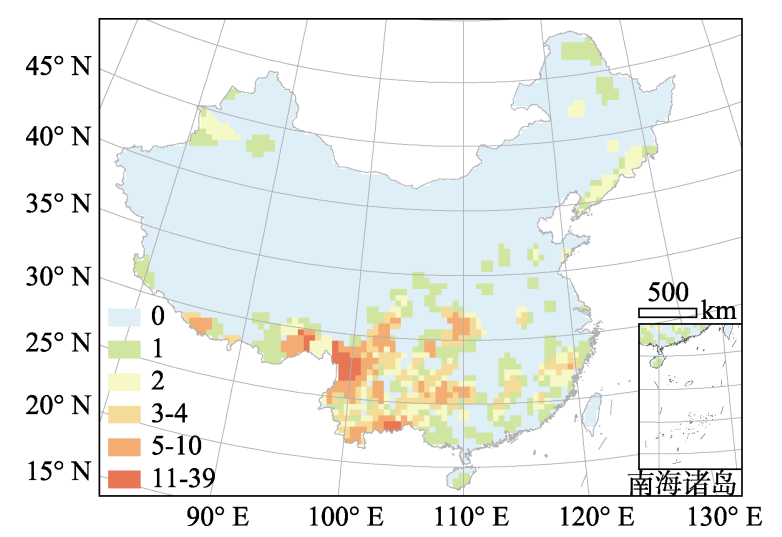

图4 蓄薇科内保护薄弱物种的物种多样性格局。保护薄弱 物种定义为狭域物种 (分布区最小的 $25 \%$ 物种)与受保护较 弱的物种(分布范围被保护区覆盖的网格数最小的 $25 \%$ )的 交集。

Fig. 4 Species richness pattern of poorly protected species in Rosaceae. The definition of poorly protected species is the intersection between narrowly-ranged species (bottom 25\% of range sizes) and the species whose distributed grid cells are less protected (bottom 25\% numbers of distributed grids covered by natural reserves).

显示蓄微科物种分布与水热条件、气候季节性有较 好的关联, 且气候季节性的作用和水热条件相反 (附录IV)。其中, 水热条件主要通过影响植物生理活 动限制植物的分布, 从而影响物种多样性。关于蓄 微科及其他类群植物生理的研究表明, 干旱或寒冷 会降低叶片的气体交换速率, 并直接减少光合作用 所需的水分, 从而影响光合速率(Schneider \& Childers, 1941; Xu et al., 2016)。这说明, 干旱或寒冷可 能通过限制植物光合作用从而限制植物在水热条件 较恶劣的地区分布。此外, 干旱还会影响蓄薇科植 物的结实率(Morales et al., 2013), 而寒冷会降低植 株的水分运输效率(Cavender-Bares et al., 2005), 也 会限制蓄薇科植物向更为干旱和寒冷的区域分布。
而气候季节性强的区域气候波动大，容易出现极端 气候, 对植物的生存形成挑战, 故气候季节性和生 物多样性呈负相关关系(Schmitt et al., 2013; Shreatha et al., 2018)。

在所有环境因子中，蓄薇科植物多样性与水分 因子的相关性最强(表2), 远强于其与温度因子的相 关性。这些结果说明蓄薇科全体物种及各资源类型 的物种多样性格局主要受水分影响。本研究的发现 与以往关于东亚地区木本植物多样性格局主导因子 的研究结果不同。比如, Wang等(2011)利用中国全部 木本植物的分布图, 研究了中国木本植物物种多样 性格局的主导因子, 发现冬季低温是中国木本植物 多样性格局的主导因子, 而冬季低温主要是通过限 制热带起源物种的向北扩散而决定东亚地区的木本 植物多样性格局。这可能是因为蓄薇科主要起源于 东亚的温带地区(Aldasoro et al., 2005; Oh \& Potter, 2005; Lo et al., 2009; Dobeš \& Paule, 2010; Chin et al., 2014), 有倾向于保留其祖先温带生态位的趋 势(Xu et al., 2013), 对寒冷的耐受性较强, 故而对 温度等因子的响应较水分因子弱; 而中国全部木本 植物中有大量热带起源的类群, 更倾向于保留祖先 的热带生态位, 对冬季低温的响应较强(Wang et al., 2011)。蓄薇科系统进化研究显示, 东亚温带区域是 蓄薇科重要的起源中心(Aldasoro et al., 2005; Oh \& Potter, 2005; Lo et al., 2009; Dobeš \& Paule, 2010)。 Chin等(2014)分析了广义李属(Prunus) 全球 81 个物 种的基因序列，构建谱系树，并确定分布在全球各 区域物种的年龄，确定该属在6 100万年前由东亚温 带地区起源，并逐步向全球其他地区扩散。基因证 据显示广义李属温带的落叶类群比热带的常绿类群 更为古老, 热带类群是由温带类群经杂交形成的新 分支(Chin et al., 2014)。起源于温带的蓄薇科植物由 于受祖先生态位保守性的限制, 可能难以扩散到环 境不同的热带地区(Xu et al., 2013), 从而形成了亚 热带山地地区物种较热带多的现象(图1)。

LGM以来的气候变化是影响植物地理分布的 重要因素, 气候变化大的区域, 物种倾向于发生迁 移和绝灭; 而气候变化小的区域则可能成为避难所, 容纳更多种类的植物(Sandel et al., 2011; Liu et al., 2017)。广义线性回归和RDA分析的结果均显示, LGM以来的气候变化对中国蓄薇科物种分布和物 种多样性格局具有显著的影响。在LGM以来气候变 
化较大以及气候变化空间迁移速率较高的地区, 蓄 微科植物多样性则较低(表2; 附录IV)。为进一步分 析LGM以来的气候变化与蓄薇科物种多样性格局 的关系, 我们篮选出对蓄薇科物种多样性影响较大 的anomaly_MAT, velocity_MAT, velocity_AP 3 个因 子, 显示了其分布格局(附录IV)。结果显示, 南方地 区受LGM时期以来气候变化影响较小, 而东北、西 北和青藏地区则受影响较大。受LGM以来气候变化 影响较小的区域与菩薇科物种多样性热点地区相一 致(附录IV, 图1)。这表明LGM以来气候变化越小的 地区物种多样性越高。我们的结果与关于北半球其 他地区和其他类群物种多样性格局的研究结果是一 致的。比如, Wang等(2012a, 2012b)发现, 中国木本 植物的狭域种分布主要可能受LGM以来气候变化 的显著影响。Montoya等(2007)评估了LGM以来的气 候变化对北美和欧洲树木多样性格局的影响, 发现 LGM结束后的冰川退缩时间显著影响了这两个大 陆的植物多样性格局。类似的, Svenning 和 Skov (2007b) 及 Normand等(2011) 对欧洲树木的研究、

Araújo和Rahbek (2008) 对欧洲两栖类和爬行类动物 多样性的研究以及Hawkins和Porter (2003)对北美哺 乳动物和鸟类多样性的研究, 均发现LGM以来的气 候变化显著影响了这些地区的物种多样性格局。

\subsection{2 生境异质性与地质变化的作用}

山区物种较其他地形多, 可能主要是由空间上 的生境异质性和时间上的地质-进化协同作用共同 导致的 (Wang et al., 2012a; Stein et al., 2014; Shrestha et al., 2018)。我们的结果显示, 横断山区是 蓄微科的主要物种多样性热点地区(图1), 这与以往 对横断山区物种多样性格局的研究是一致的。横断 山区作为全球生物多样性的一个热点地区, 不仅是 萻微科多样性的热点地区, 也是很多其他类群的热 点地区。这一区域拥有超过9 000种维管束植物, 且 具有很高的特有性(中国科学院青藏高原综合科学 考察队, 1993; Myers et al., 2000; Wang et al., 2012a)。这一地区巨大的生境异质性可能对热点地 区的形成起到了重要作用。横断山区地处喜马拉雅 山系东缘, 青藏高原的隆起给该地区带来复杂的地 形和多种不同的生境。复杂的地形不仅为物种提供 栖息地、促进物种共存, 在极端气候下还成为生物 的避难所(López-Pujol et al., 2011)。与横断山区类似, 四川盆地周边的山区同样具有较为复杂的地形, 可
以为菩薇科植物提供更加多样化的生存环境, 从而 容纳更多的物种(López-Pujol et al., 2011)。本文关于 物种多样性和物种分布与环境因子关系的结果显示, 生境异质性与蓄薇科物种多样性存在正相关关系 (表2), 很好地支持了前述观点。此外, 除了较高的 生境异质性, 横断山区在地质历史上经历了比较剧 烈的地质变化(Zhong \& Ding, 1996), 从而促进了物 种的迅速形成, 成为新物种的“摇篮” (Fjeldså et al., 2012; Hughes \& Atchison, 2015)。比如, Xing和Ree (2017)分析了19个植物类群在横断山区、青藏高原 区和东亚其他地区的进化, 发现横断山区自约 1000 万年以来一直是东亚地区植物多样性的重要“摇篮”, 很多植物类群在横断山区发生快速分化并向周边地 区扩散。

\section{2 蔷薇科的资源植物}

本研究收集了较为翔实的资料, 在中国菩薇科 植物名录的基础上, 补充了各物种常见的经济用途 (包括食用、园林绿化、药用和水果种质资源, 见附 录II), 可以为萻薇科植物资源开发与保护提供参 考。本名录包含了常见野生花卉山桃(Amygdalus davidiana)、海棠花(Malus spectabilis)、月季(Rosa chinensis), 观叶植物平枝栒子(Cotoneaster horizontalis)、石楠 (Photinia serratifolia)、花楸 (Sorbus pohuashanensis), 常见水果樱桃 (Cerasus pseudocerasus)、李(Prunus salicina)、沙梨(Pyrus pyrifolia), 常用药材翻白草(Potentilla discolor)、地榆(Sanguisorba officinalis)等, 这些植物在中国人的生产生 活中扮演着重要角色。通过该名录可以看出, 中国 蓄薇科植物中超过一半具有药用价值, 超过 $40 \%$ 可 以成为培育水果新品种的种质资源，同时有 $30 \%$ 的 物种具有园林绿化和观赏价值, 并可以成为培育新 品种花卉苗木的种质资源(表4)。

由于本研究去除了人工杂交种以及自然分布区 无法确定的栽培种, 实际上有大量的花卉和水果品 种没有被纳入本研究的考察范围, 包括著名花卉西 府海棠 (Malus × micromalus)、梅花 (Armeniaca mume), 传统水果桃(Amygdalus persica)、杏(Armeniaca vulgaris)、枇杷(Eriobotrya japonica)等。此外, 全国广泛种植的苹果 (Malus domestica)、草莓 (Fragaria $\times$ ananassa) 等水果属外来种 $(\mathrm{Li}, 1999$; Liston et al., 2014), 也不在本研究的考察范围之内。 但上述物种在我国农业经济中有着重要作用。比如

www.plant-ecology.com 
我国是全球最大的苹果生产国, 年产量超过 4000 万 吨, 有数千万苹果产业从业人员, 相关产业年产值 超过3 000亿元(王朱荣, 2017), 对服务“三农”, 脱贫 攻坚具有重大意义(王朱莹, 2017)。这说明蓄薇科的 经济价值可能远超本研究评估的水平, 而野生蓄薇 科植物作为栽培种的种质资源, 其保护价值也日益 凸显。另外, 对于其他资源类型的蓄薇科植物, 如蜜 源植物、油料作物、用材树种、牧草与纤维植物等, 由于物种数较少或资料缺乏等原因, 本文没有加以 评估。对于这些资源物种的多样性研究与保护有待 进一步探索。

\section{3 蓄薇科资源植物的保护现状和保护弱点}

食用植物多样性热点地区和其他资源植物有较 大差异(图2)。这些差异主要体现在: 食用植物多样 性热点地区主要集中在秦岭、大巴山、巫山等山脉, 但不包括横断山区(图2)。菩薇科资源植物的“三类 热点” 主要出现在横断山区, 正是由于该地区缺乏 食用植物热点地区所致(图2, 图3)。食用植物多样性 在横断山区较低可能与人类聚居地的分布有关。秦 岭、大巴山、巫山等地距离人类聚居历史悠久的关 中平原、江汉平原和四川盆地等距离较近, 人类对 植物开发利用时间较长; 相反, 横断山区对人类、 特别是历史时期的人类来说相对难以逾越, 即使其 物种丰富, 但被人类作为食物来源的物种可能比较 有限。

我国的保护区分布在空间上是不均衡的(图3), 青藏高原和东北地区保护面积较大, 而东部和南部 地区则保护面积较小。但对于蓄薇科来说, 最重要 的资源植物热点地区 (即“四类热点”地区) 的保护程 度相对较高(图3; 表3), 保护区覆盖面积比例高于 全国平均水平。但需要指出的是, 在“四类热点”中 仍有 $20 \%-30 \%$ 的区域没有被保护区覆盖。对于其他 级别的热点地区, 保护则相对缺乏。从蓄薇科全部 物种来看, 其保护区覆盖面积比例仍没有达到全国 平均水平 (表 3), 这与蓄薇科的经济价值是不匹 配的。

保护薄弱种的多样性格局显示, 横断山区是保 护薄弱种分布最为集中的区域(图4, 由于台湾岛保 护区分布数据缺失, 对该岛保护薄弱物种不作评 估)。这说明, 在横断山区应有针对性地加强对蓄薇 科物种、特别是资源植物的保护规划。类似地, 云 南东南部和西藏东南部的部分地区同样也是保护薄
弱物种集中分布的地区。然而，近年来青藏高原东 缘地区的土地利用变化对该地区的生物多样性造成 了较为严重的威胁(Salick et al., 2005), 故而这些地 区同时作为多样性热点地区和保护薄弱物种集中分 布的地区，在植物多样性保护，特别是资源植物多 样性保护方面需要引起更多关注(Forest et al., 2007)。

在生物多样性保护规划时, 考虑物种之间的进 化关系有助于更合理地保护一个地区的进化历史 (Laity et al., 2015)。但由于数据限制, 本研究主要着 眼于物种多样性，未考虑进化因素对资源植物、保 护薄弱物种和保护区规划的影响(Faith, 1992), 在未 来研究中应进一步分析菩薇科进化及其对资源植物 保护规划的作用。本研究通过对蓄薇科各属的资源 植物禀赋及受保护状况的分析, 显示出蓄薇科内不 同属之间资源禀赋的巨大差异(表1)，这表明在对该 类群进行保护时, 需要根据各个属的分布状况有针 对性地进行保护(Araiso \& Dunford, 2005)。然而, 现 有的保护体系并不能兼顾蓄薇科各个属的保护，甚 至在资源物种比较集中的大属中也出现了较多的保 护薄弱物种(如悬钩子属, 表1)。因此, 对各个属的 针对性保护，应充分考虑各属的资源禀赋，针对各 资源类型的植物开展保护, 让保护区的保护功能更 加合理高效。

\section{致谢 感谢北京大学苏香燕在Arcgis制图工作中给} 予的帮助。感谢北京大学Nawal Shrestha在保护区分 析算法上给予的帮助。

\section{参考文献}

Ai TM (2016). Medicinal Flora of China. Vol. 3. Peking University Medical Press, Beijing. [艾铁民 (2016). 中国药 用植物志. 第3卷. 北京大学医学出版社, 北京.]

Aldasoro JJ, Aedo C, Navarro C (2005). Phylogenetic and phytogeographical relationships in Maloideae (Rosaceae) based on morphological and anatomical characters. BlumeaBiodiversity, Evolution and Biogeography of Plants, 50, $3-32$.

Amsellem L, Noyer JL, Le BT, Hossaertmckey M (2000). Comparison of genetic diversity of the invasive weed $R u$ bus alceifolius Poir. (Rosaceae) in its native range and in areas of introduction, using amplified fragment length polymorphism (AFLP) markers. Molecular Ecology, 9, 443-455.

Araiso T, Dunford HB (2005). A test of the higher-taxon approach in the identification of candidate sites for marine 
reserves. Biodiversity and Conservation, 14, 3151-3168.

Araújo MB, Rahbek C (2008). Quaternary climate changes explain diversity among reptiles and amphibians. Ecography, 31, 8-15.

Brehm JM, Maxted N, Martins-Loução MA, Ford-Lloyd BV (2010). New approaches for establishing conservation priorities for socio-economically important plant species. Biodiversity and Conservation, 19, 2715-2740.

Brown JH (2014). Why are there so many species in the tropics? Journal of Biogeography, 41, 8-22.

Bureau of Local Products and Wastes, Ministry of Commerce, People's Republic of China, Institute of Botany, Chinese Academy of Sciences (2012). Flora of Economic Plants of China. Science Press, Beijing. [中华人民共和国商业部 土产废品局, 中国科学院植物研究所 (2012). 中国经济 植物志. 科学出版社, 北京.]

Cavender-Bares J, Cortes P, Rambal S, Joffre R, Miles B, Rocheteau A (2005). Summer and winter sensitivity of leaves and xylem to minimum freezing temperatures: A comparison of co-occurring mediterranean oaks that differ in leaf lifespan. New Phytologist, 168, 597-612.

Chin SW, Shaw J, Haberle R, Wen J, Potter D (2014). Diversification of almonds, peaches, plums and cherries- Mmolecular systematics and biogeographic history of Prunus (Rosaceae). Molecular Phylogenetics \& Evolution, 76, 34-48.

Collins JP, Halliday T (2005). Forecasting changes in amphibian biodiversity: Aiming at a moving target. Philosophical Transactions of the Royal Society of London B: Biological Sciences, 360, 309-314.

Currie DJ (1991). Energy and large-scale patterns of animaland plant-species richness. The American Naturalist, 137, 27-49.

Dobeš C, Paule J (2010). A comprehensive chloroplast DNAbased phylogeny of the genus Potentilla (Rosaceae): Implications for its geographic origin, phylogeography and generic circumscription. Molecular Phylogenetics \& Evolution, 56, 156-175.

Dong YC, Liu X (2006). Crops and Their Wild Relatives in China. China Agricultural Press, Beijing. [董玉琛, 刘旭 (2006). 中国作物及其野生近缘植物. 中国农业出版社, 北京.]

Faith DP (1992). Conservation evaluation and phylogenetic diversity. Biological Conservation, 61, 1-10.

Fan L, Zhang MY, Liu QZ, Li LT, Song Y, Wang LF, Zhang SL, Wu J (2013). Transferability of newly developed pear SSR markers to other Rosaceae species. Plant Molecular Biology Reporter, 31, 1271-1282.

Fang JY, Wang ZH, Tang ZY (2011). Atlas of Woody Plants in China: Distribution and Climate. Springer-Verlag, Berlin.

Fjeldså J, Bowie RCK, Rahbek C (2012). The role of mountain ranges in the diversification of birds. Annual Review of
Ecology Evolution \& Systematics, 43, 249-265.

Forest F, Grenyer R, Rouget M, Davies TJ, Cowling RM, Faith DP, Balmford A, Manning JC, Proches S, van der Bank M, Reeves G, Hedderson TAJ, Savolainen V (2007). Preserving the evolutionary potential of floras in biodiversity hotspots. Nature, 445, 757-760.

Gaston KJ (2000). Global patterns in biodiversity. Nature, 405, 220-227.

Gent PR, Danabasoglu G (2011). Response to increasing southern hemisphere winds in CCSM4. Journal of Climate, 24, 4992-4998.

Hawkins BA, Porter EE (2003). Relative influences of current and historical factors on mammal and bird diversity patterns in deglaciated North America. Global Ecology \& Biogeography, 12, 475-481.

Hijmans RJ, Cameron SE, Parra JL, Jones PG, Jarvis A (2005). Very high resolution interpolated climate surfaces for global land areas. International Journal of Climatology, 25, 1965-1978.

Hu XS (1955). Handbook of Economic Plants. Science Press, Beijing. [胡先骕 (1955). 经济植物手册. 科学出版社, 北京.]

Hughes CE, Atchison GW (2015). The ubiquity of alpine plant radiations: From the Andes to the Hengduan Mountains. New Phytologist, 207, 275-282.

Jetz W, Rahbek C (2002). Geographic range size and determinants of avian species richness. Science, 297, 1548-1551.

Kerr JT, Packer L (1997). Habitat heterogeneity as a determinant of mammal species richness in high-energy regions. Nature, 385, 252-254.

Kimura MK, Uchiyama K, Nakao K, Moriguchi Y, San Jose-Maldia L, Tsumura Y (2014). Evidence for cryptic northern refugia in the last glacial period in Cryptomeria japonica. Annals of Botany, 114, 1687-1700.

Laity T, Laffan SW, González-Orozco CE, Faith DP, Dan FR, Byrne M, Miller JT, Grayn D, Costion C, Moritz CC, Newport K (2015). Phylodiversity to inform conservation policy: An Australian example. Science of the Total Environment, 534, 131-143.

Lee S, Wen J (2001). A phylogenetic analysis of Prunus and the Amygdaloideae (Rosaceae) using its sequences of nuclear ribosomal DNA. American Journal of Botany, 88, 150-160.

Li Y (1999). An investigation and studies on the origin and evolution of Malus domestica Borkh. in the world. Acta Horticulturae Sinica, 26, 213-220.

Lin-Wang K, Bolitho K, Grafton K, Kortstee A, Karunairetnam S, Mcghie TK, Espley RV, Hellens RP, Allan AC (2010). An R2R3 MYB transcription factor associated with regulation of the anthocyanin biosynthetic pathway in Rosaceae. BMC Plant Biology, 10, 50-66.

Liston A, Cronn R, Ashman TL (2014). Fragaria: A genus

www.plant-ecology.com 
with deep historical roots and ripe for evolutionary and ecological insights. American Journal of Botany, 101, 1686-1699.

Liu YM, Huang QN (2012). Ornamental Plant Species 1000. Fujian Science and Technology Press, Fuzhou. [刘与明, 黄全能 (2012). 园林植物 1000 种. 福建科学技术出版 社, 福州.]

Liu YP, Shen ZH, Wang QG, Su XY, Zhang WJ, Shrestha N, Xu XT, Wang ZH (2017). Determinants of richness patterns differ between rare and common species: Implications for Gesneriaceae conservation in China. Diversity \& Distributions, 23, 235-246.

Lo EYY, Stefanović S, Christensen KI, Dickinson TA (2009). Evidence for genetic association between East Asian and western North American Crataegus L. (Rosaceae) and rapid divergence of the eastern North American lineages based on multiple DNA sequences. Molecular Phylogenetics \& Evolution, 51, 157-168.

Loarie SR, Duffy PB, Hamilton H, Asner GP, Field CB, Ackerly DD (2009). The velocity of climate change. Nature, 462, 1052-1055.

López-Pujol J, Zhang FM, Sun HQ, Ying TS, Ge S (2011). Centres of plant endemism in China: Places for survival or for speciation? Journal of Biogeography, 38, 1267-1280.

Mccabe GJJ, Wolock DM, Hay LE, Ayers MA (1990). Effects of climatic change on the Thornthwaite moisture index. Jawra Journal of the American Water Resources Association, 26, 633-643.

Mcglone MS (1996). When history matters: Scale, time, climate and tree diversity. Global Ecology \& Biogeography Letters, 5, 309-314.

Mendoza W, Cano A (2011). Diversity of the genus Polylepis (Rosaceae, Sanguisorbeae) in the Peruvian Andes. Revista Peruana De Biología, 18, 197-200.

Montoya D, Rodríguez MA, Zavala MA, Hawkins BA (2007). Contemporary richness of holarctic trees and the historical pattern of glacial retreat. Ecography, 30, 173-182.

Morales CG, Pino MT, Pozo AD (2013). Phenological and physiological responses to drought stress and subsequent rehydration cycles in two raspberry cultivars. Scientia Horticulturae, 162, 234-241.

Myers N, Mittermeier RA, Mittermeier CG, Fonseca GA, Kent $\mathrm{J}$ (2000). Biodiversity hotspots for conservation priorities. Nature, 403, 853-858.

Normand S, Ricklefs RE, Flemming S, Jesper B, Oliver T, Jens-Christian S (2011). Postglacial migration supplements climate in determining plant species ranges in Europe. Proceedings of the Royal Society B: Biological Sciences, 278, 3644-3653.

O’Brien EM (1993). Climatic gradients in woody plant species richness: Towards an explanation based on an analysis of southern Africa's woody flora. Journal of Biogeography,
20, 181-198.

Oh SH, Potter D (2005). Molecular phylogenetic systematics and biogeography of tribe Neillieae (Rosaceae) using DNA sequences of cpDNA, rDNA, and LEAFY. American Journal of Botany, 92, 179-192.

Orme CDL, Davies RG, Burgess M, Eigenbrod F, Pickup N, Olson VA, Webster AJ, Ding TS, Rasmussen PC, Ridgely RS, Stattersfield AJ, Bennett PM, Blackburn TM, Gaston KJ, Owens PF (2005). Global hotspots of species richness are not congruent with endemism or threat. Nature, 436, 1016-1019.

Palmer MW, White PS (1994). Scale dependence and the speciesarea relationship. The American Naturalist, 144, 717-740.

Peyravi M (2015). Prioritizing areas for conservation of Rosaceae in Iran based on the geographic distribution analysis. Iranian Journal of Botany, 21, 47-57.

Potter D, Eriksson T, Evans RC, Oh S, Smedmark JEE, Morgan DR, Kerr M, Roberston KR, Arsenault M, Dickinson TA, Campbell CS (2007). Phylogeny and classification of Rosaceae. Plant Systematics \& Evolution, 266, 5-43.

Qin HN, Yang Y, Dong SY, He Q, Jia Y, Zhao LN, Yu SX, Liu HY, Liu B, Yan YH, Xiang JY, Xia NH, Peng H, Li ZY, Zhang ZX, He XJ, Yin LK, Lin YL, Liu QR, Hou YT, Liu Y, Liu QX, Cao W, Li JQ, Chen SL, Jin XH, Gao TG, Chen WL, Ma HY, Geng YY, Jin XF, Chang CY, Jiang H, Cai L, Zang CX, Wu JY, Ye JF, Lai CJ, Liu B, Lin QW, Xue NX (2017). Threatened species list of China's higher plants. Biodiversity Science, 25, 696-744. [覃海宁, 杨永, 董仕勇, 何强, 贾渝, 赵莉娜, 于胜祥, 刘慧圆, 刘博, 严岳鸿，向建英，夏念和，彭华，李振宇，张志翔，何兴 金, 尹林克，林余霖，刘全儒，侯元同，刘演，刘启新， 曹伟，李建强，陈世龙，金效华，高天刚，陈文俐，马海 英, 耿玉英，金孝锋，常朝阳，蒋宏，蔡蕾，蔵春傘金，武 建勇, 叶建飞, 赖阳均, 刘冰, 林秦文, 薛纳新 (2017). 中国高等植物受威胁物种名录. 生物多样性, 25 , 696-744.]

Ricklefs RE (2004). A comprehensive framework for global patterns in biodiversity. Ecology Letters, 7, 1-15.

Ru S, Main D, Evans K, Peace C (2015). Current applications, challenges, and perspectives of marker-assisted seedling selection in Rosaceae tree fruit breeding. Tree Genetics \& Genomes, 11, 8. DOI: 10.1007/s11295-015-0834-5.

Salick J, Yang YP, Amend A (2005). Tibetan land use and change near Khawa Karpo, eastern Himalayas. Economic Botany, 59, 312-325.

Sandel B, Arge L, Dalsgaard B, Davies RG, Gaston KJ, Sutherland WJ, Svenning JC (2011) The influence of Late Quaternary climate-change velocity on species endemism. Science, 334, 660-664.

Schmitt CB, Senbeta F, Woldemariam T, Rudner M, Denich M (2013). Importance of regional climates for plant species distribution patterns in moist Afromontane forest. Journal 
of Vegetation Science, 24, 553-568.

Schneider GW, Childers NF (1941). Influence of soil moisture on photosynthesis, respiration and transpiration of apple leaves. Plant Physiology, 16, 565-583.

Scientific Investigation Team for Qinghai-Xizang Plateau, Chinese Academy of Sciences (1993). Vascular Plants in Hengduan Mountains. Science Press, Beijing. [中国科学 院青藏高原综合科学考察队 (1993). 横断山区维管植 物. 科学出版社, 北京.]

Sher H, Ali H, Rehman S (2012). Identification and conservation of important plant areas (IPAs) for the distribution of medicinal, aromatic and economic plants in the Hindukush-Himalaya mountain range. Pakistan Journal of Botany, 44, 187-194.

Shi S, Li J, Sun J, Yu J, Zhou S (2013). Phylogeny and classification of Prunus sensu lato (Rosaceae). Journal of Integrative Plant Biology, 55, 1069-1079.

Shrestha N, Su XY, Xu XT, Wang ZH (2018). The drivers of high Rhododendron diversity in southwest China: Does seasonality matter? Journal of Biogeography, 45, 438-447.

Staff Room of Pharmacognosy of Department of Pharmacy of Second Military Medical University (1960). Illustrated Handbook of Chinese Medicinal Plants. Shanghai Education Press, Shanghai. [第二军医大学药学系生药学教研 室 (1960). 中国药用植物图鉴. 上海教育出版社, 上 海.]

Stein A, Gerstner K, Kreft H (2014). Environmental heterogeneity as a universal driver of species richness across taxa, biomes and spatial scales. Ecology Letters, 17, 866-880.

Svenning JC, Skov F (2007a). Ice age legacies in the geographical distribution of tree species richness in Europe. Global Ecology \& Biogeography, 16, 234-245.

Svenning JC, Skov F (2007b). Could the tree diversity pattern in Europe be generated by postglacial dispersal limitation? Ecology Letters, 10, 453-460.

Thornthwaite C, Hare FK (1955). Climatic classification in forestry. Unasylva, 9, 51-59.

Wang RX (2010). Pictures of Ornamental Plants. China Machine Press, Beijing. [汪荣先 (2010). 园林景观植物树 木图典. 机械工业出版社, 北京.]

Wang SY, Xu XT, Shrestha N, Zimmermann NE, Tang ZY, Wang ZH (2017). Response of spatial vegetation distribution in China to climate changes since the last glacial maximum (LGM). PLOS ONE, 12, e0175742. DOI:10.1371/journal.pone.0175742.

Wang ZH, Fang JY, Tang ZY, Lin X (2011). Patterns, determinants and models of woody plant diversity in China. Proceedings of the Royal Society B: Biological Sciences, 278, 2122-2132.

Wang ZH, Fang JY, Tang ZY, Lin X (2012a). Relative role of contemporary environment versus history in shaping di- versity patterns of China's woody plants. Ecography, 35, 1124-1133.

Wang ZH, Fang JY, Tang ZY, Shi L (2012b). Geographical patterns in the beta diversity of China's woody plants: The influence of space, environment and range size. Ecography, 35, 1092-1102.

Wang ZH, Tang ZY, Fang JY (2009). The species-energy hypothesis as a mechanism for species richness patterns. Biodiversity Science, 17, 613-624. [王志恒, 唐志尧, 方精 云 (2009). 物种多样性地理格局的能量假说. 生物多样 性, 17, 613-624.]

Wang ZY (2017). Apple futures: Based on serving for "Three Rural" issues and to help anti-poverty. China Securities Journal, 2017-12-12. [王朱莹 (2017). 苹果期货: 立足 服务“三农”助力脱贫攻坚. 中国证券报, 2017-12-12.]

Watanabe S, Hajima T, Sudo K, Nagashima T, Takemura T, Okajima H, Nozawa T, Kawase H, Abe M, Yokohata T, Ise T, Sato H, Kato E, Takata K, Emori S, Kawamiya M (2011). MIROC-ESM 2010: Model description and basic results of CMIP5-20c3m experiments. Geoscientific Model Development, 4, 845-872.

Wells CE, Glenn DM, Eissenstat DM (2002). Changes in the risk of fine-root mortality with age: A case study in peach, Prunus persica (Rosaceae). American Journal of Botany, $89,79-87$.

Wheeler JK, Sperry JS, Hacke UG, Hoang N (2005). Inter-vessel pitting and cavitation in woody Rosaceae and other vesselled plants: A basis for a safety versus efficiency trade-off in xylem transport. Plant, Cell \& Environment, 28, 800-812.

Whittaker R, Nogues-Bravo D, Araújo M (2007). Geographical gradients of species richness: A test of the water-energy conjecture of Hawkins et al. (2003) using European data for five taxa. Global Ecology \& Biogeography, 16, 76-89.

Wiens JJ, Donoghue MJ (2004). Historical biogeography, ecology and species richness. Trends in Ecology and Evolution, 19, 639-644.

Wu ZY, Raven P (1994-2009). Flora of China. Science Press \& Missouri Botanical Garden Press, Beijing \& St Louis.

Xiang YZ, Huang C, Hu Y, Wen J, Li SS, Yi TS, Chen HY, Xiang J, Ma H (2017). Well-resolved Rosaceae nuclear phylogeny facilitates feological time and genome duplication analyses and ancestral fruit character reconstruction. Molecular Biology and Evolution, 34, 262-281.

Xing Y, Ree RH (2017). Uplift-driven diversification in the Hengduan Mountains, a temperate biodiversity hotspot. Proceedings of the National Academy of Sciences of the United States of America, 114, 3444-3451.

Xu XT, Wang ZH, Rahbek C, Lessard J, Fang JY (2013). Evolutionary history influences the effects of water-energy dynamics on oak diversity in Asia. Journal of Biogeography, 40, 2146-2155.

www.plant-ecology.com 
Xu XT, Wang ZH, Rahbek C, Sanders NJ, Fang JY (2016). Geographical variation in the importance of water and energy for oak diversity. Journal of Biogeography, 43, $279-288$.

Ye HG, Zou B, Zeng FY (2014). Chinese Medicinal Plants. Vol. 1. Chemical Industry Press, Beijing. [叶华谷, 邹滨, 曾飞燕 (2014). 中国药用植物(一). 化学工业出版社, 北京.]

Yu DJ, Lu LT, Gu CZ, Li CL, Guan KJ (1989). Flora Reipublicae Popularis Sinicae. Vol. 36-38 (Rosaceae, Connaraceae). Science Press, Beijing. [俞德浚, 陆玲娣, 谷粹 芝, 李朝銮, 关克俭 (1989). 中国植物志. 第36-38卷 (蓄薇科、牛栓藤科). 科学出版社, 北京.]

Zhang SD, Jin JJ, Chen SY, Chase MW, Soltis DE, Li HT, Yang JB, Li DZ, Yi TS (2017). Diversification of Rosaceae since the late Cretaceous based on plastid phylogenomics. New Phytologist, 214, 1355-1367.
Zhang ZJ, He JS, Li JS, Tang ZY (2015). Distribution and conservation of threatened plants in China. Biological Conservation, 192, 454-460.

Zheng HC, Shun QS, Yu GD, Feng ZJ, Quan SC (2003). Chinese Edible Herbs. Vol. Plants. Shanghai Lexicographical Publishing House, Shanghai. [郑汉臣, 顺庆生, 余国奠, 冯志坚, 全山丛 (2003). 中国食用本草, 植物卷. 上海 辞书出版社, 上海.]

Zhong DL, Ding L (1996). Rising process of the QinghaiXizang (Tibet) Plateau and its mechanism. Science in China Series D, 39, 369-379.

Zhou HY (2009). Illustrated Handbook of Landscape Plant Species. China Forestry Publishing House, Beijing. [周洪 义 (2009). 园林景观植物图鉴. 中国林业出版社, 北 京.]

责任编委: 康慕谊 责任编辑: 李 敏

附录I 蓄薇科野生水果种质资源参考文献列表

Supplement I References of wild fruit germplasm resources of Rosaceae in China http://www.plant-ecology.com/fileup/PDF/cjpe.2018.0091-S1.pdf

附录II 本文所使用的蓄薇科物种名录、物种所属资源类别及濒危等级与保护情况

Supplement II Species list of all Rosaceae species, resource species, endangered species in China and conservation status of those species

http://www.plant-ecology.com/fileup/PDF/cjpe.2018.0091-S2.pdf

附录III 各环境变量之间的Pearson相关系数

Supplement III Pearson correlation coefficients between environmental variables

http://www.plant-ecology.com/fileup/PDF/cjpe.2018.0091-S3.pdf

附录IV 中国LGM以来气候变化指标的空间分布图

Supplement IV Spatial distributions of variables of climate change since last glacial maximum in China http://www.plant-ecology.com/fileup/PDF/cjpe.2018.0091-S4.pdf

\section{附录 $\mathbf{V}$ 中国蓄薇科物种分布格局与环境因子的关系}

Supplement V Relationships between species distribution patterns of Rosaceae species and environmental variables in China

http:/www.plant-ecology.com/fileup/PDF/cjpe.2018.0091-S5.pdf 